\title{
Marketing and Poverty Alleviation: Synergizing Research, Education, and Outreach Through the Subsistence Marketplaces Approach
}

\author{
Madhubalan Viswanathan \\ University of Illinois at Urbana-Champaign \\ Arun Sreekumar \\ University of Illinois, Urbana-Champaign
}

Follow this and additional works at: https://digitalcommons.uri.edu/mgdr

Part of the Anthropology Commons, Economics Commons, Marketing Commons, Other Business Commons, Public Affairs, Public Policy and Public Administration Commons, and the Sociology Commons

\section{Recommended Citation}

Viswanathan, Madhubalan and Sreekumar, Arun (2017) "Marketing and Poverty Alleviation: Synergizing Research, Education, and Outreach Through the Subsistence Marketplaces Approach," Markets, Globalization \& Development Review. Vol. 2: No. 4, Article 2.

DOI: 10.23860/MGDR-2017-02-04-02

Available at: https://digitalcommons.uri.edu/mgdr/vol2/iss4/2

This Article is brought to you for free and open access by DigitalCommons@URI. It has been accepted for inclusion in Markets, Globalization \& Development Review by an authorized editor of DigitalCommons@URI. For more information, please contact digitalcommons-group@uri.edu. 


\section{Marketing and Poverty Alleviation: Synergizing Research, Education, and Outreach Through the Subsistence Marketplaces Approach}

\section{Cover Page Footnote}

While not specifically written as a response, this article is in the conceptual space that was opened by the MGDR inaugural issue article by Ravi Achrol and Philip Kotler. 


\section{Markets, Globalization \& Development Review}
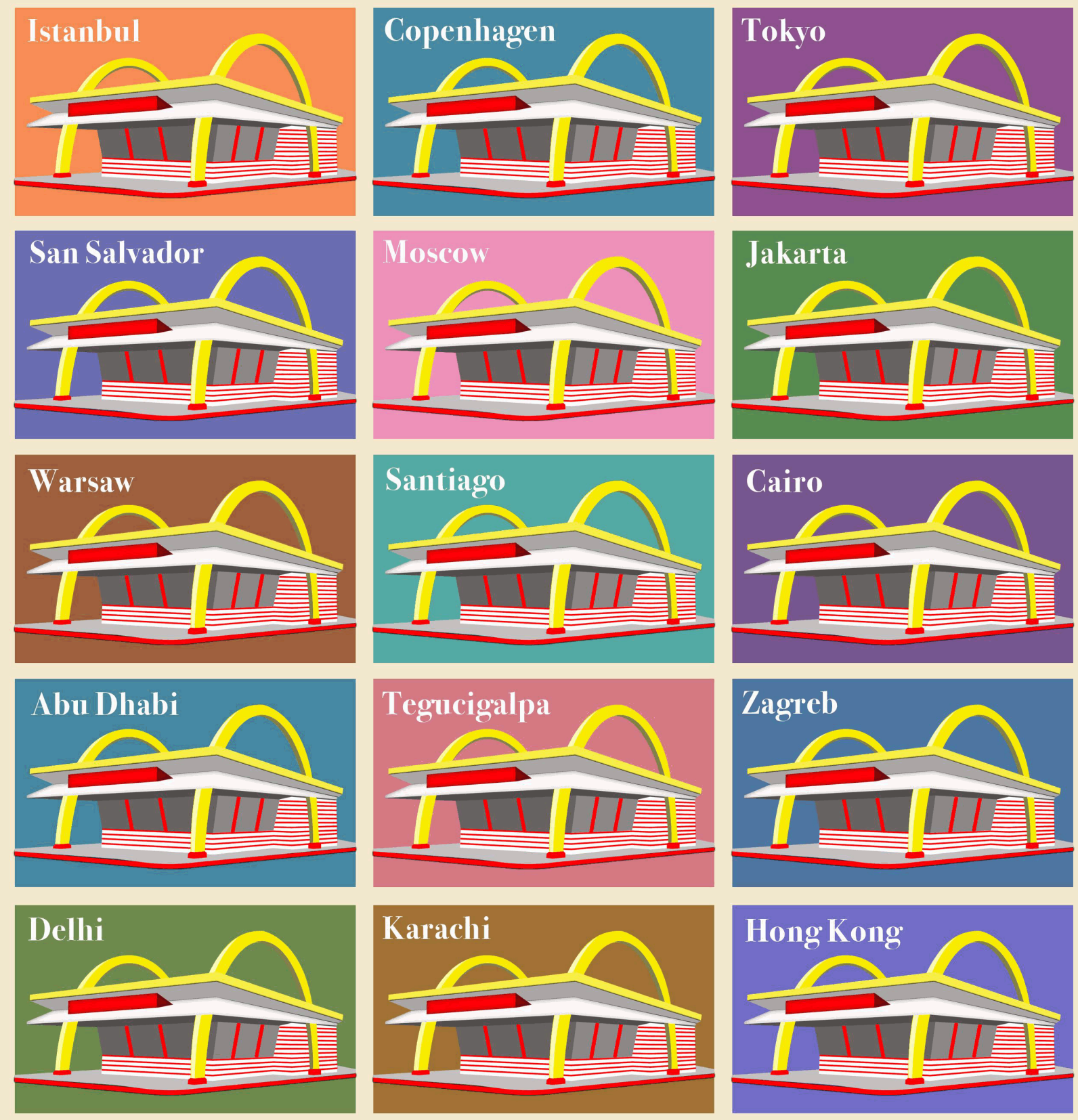

This article is available in Markets, Globalization \& Development Review: https://digitalcommons.uri.edu/mgdr/vol2/ 


\section{Marketing and Poverty Alleviation: Synergizing Research, Education, and Outreach Through the Subsistence Marketplaces Approach}

We greatly appreciate the important conversation about the role of the marketing discipline in poverty alleviation reflected in some MGDR articles (Achrol and Kotler 2016, 2017; Karnani 2017). In this article, we describe our journey through the creation and development of the stream of subsistence marketplaces, summarize our learning, and discuss implications at the intersection of the field of Marketing and poverty alleviation. We organize the article by beginning with data, that is, our experiences of the past two decades, then summarizing the learning, and drawing implications.

\section{Overview}

We have pioneered the area of subsistence marketplaces, creating unique synergies between research, teaching, and social initiatives ${ }^{1}$. Distinct from macro level economic research in impoverished contexts, or mid-level approaches, such as the base of the pyramid (BOP) approach in business strategy and marketing theory (see, e.g., Yurdakul, Atik and Dholakia 2017), this approach is rooted at the micro-level, enabling bottom up understanding of buyer and seller behaviors (Viswanathan and Rosa 2007). This micro-level perspective aims to enable subsistence marketplaces to move toward being ecologically, economically, and socially sustainable. The term, subsistence marketplaces, reflects understanding these contexts in their own right, not just as markets to sell to, but as individuals, communities, consumers, entrepreneurs, and marketplaces to learn from. This bottom-up approach beginning at the micro level is both very difficult to enact and has been neglected by different sectors such as business, government, and development/non-profit entities.

The coinage of the term, subsistence marketplaces, was deliberate - to bring out the qualitative nature of life circumstances through the term, subsistence, and to emphasize the importance of understanding preexisting marketplaces before designing solutions. Marketplaces (the arena where exchanges happen; "any sphere considered as a place where ideas, thoughts, artistic creations, etc., compete for recognition"; from Dictionary-dot-com http://www.dictionary.com/browse/marketplace ), rather than markets (as in demand or customers for products; "A demand for a particular

${ }^{1}$ http://www.business.illinois.edu/subsistence 
commodity or service"; from Oxford Dictionaries https://en.oxforddictionaries.com/definition/market), emphasizes being diametrically at the opposite end of a continuum of taking existing products to new markets. The stream also subscribes to the need to study these contexts in their own right, and not because they are a means for outside businesses or policy initiatives. Much of humanity engages in exchange, marketing, consumption, and entrepreneurship in starkly different subsistence marketplaces, worthy of study in their own right. The approach begins at the micro-level, aiming to unpack relatively broader terms such as social capital and poverty. It is bottomup, in using the insights from these marketplaces for designing solutions, developing enterprise plans, and sustainable development. In contrast to macromarketing, this is a distinctly different starting point that, in turn, has implications for meso (e.g., organizational marketing, and product development) and macro (e.g., macro-marketing, and sustainable development) levels.

Within this work, a community of researchers, students, and practitioners has been created through a series of biennial conferences. Our own efforts have generated four books, and more than 40 authored publications, and we have also edited roughly 60 refereed publications authored by scholars around the world through special issues, all profiled at this University of Illinois website: https://business.illinois.edu/subsistence/research/publications/. This community has worked in different continents around the world on topics ranging from theory to method, in urban, rural and tribal communities and post-conflict settings, using different perspectives, and studying consumption and entrepreneurship, individual and community empowerment, social and commercial enterprise development and, individual and institutional elements (Abdelnour and Branzei 2010; Jones-Christensen et al. 2010; Kolk 2015; Lindeman 2014; Mandiberg 2012; Ozanne and Saatcioglu 2007; Ruth and Hsiung 2007; Toledo-Lopez et al. 2012).

Direct educational experiences derived from our experiences on this topic, reach almost a thousand students a year at the University of Illinois, including a yearlong interdisciplinary course and a one-of-akind international immersion experience that has been ranked one of the top 10 entrepreneurship courses by Inc. Magazine. This learning experience serves as a bottom-up innovation platform with more than fifty projects led by interdisciplinary student groups (including engineering, design, and business) with commercial and social enterprises. In addition, we have taken our accumulated experiences and reached out globally to thousands of students around the world through a course on the online learning platform, Coursera. Educational materials are disseminated worldwide to educators and students through a web portal. 
This work has led to a unique marketplace literacy educational program that tens of thousands of individuals have received in eight countries - India, USA, Tanzania, Uganda, Kenya, Argentina, Honduras, and Mexico through the Marketplace Literacy Project ${ }^{2}$, a non-profit organization founded in concert with this initiative and other partners.

\section{Origins}

This journey began interestingly as a result of how consumers use numbers and words in a variety of contexts, including with package information and nutritional information, and the role of preference for numerical information in the realm of consumer psychology (e.g., Viswanathan 1993; 1996). Such work often begged the question what about those who are unable to read and comprehend the information conveyed in numbers and, as well, in words and the role of numeracy and literacy, respectively. Thus, our first deliberate study was on low-literate, low-income consumers in the US, as we organized a special session at the ACR conference in 1998 (Ritson and Viswanathan 1999). Interestingly, our pathway to this entire area was through understanding consumers at a micro-level, such a focus fitting with the core of the marketing discipline with its distinct customer focus. Though work on poverty in marketing has a long history, when looking at the highly correlated aspect of low literacy, we found work at that time in relevant disciplines that was at a macro level based on aggregate statistics or at a cognitive psychological level in terms of reading difficulties due to deficits in brain functions (Gau, Jae and Viswanathan 2012) (Viswanathan, Hastak and Gau 2009). The realm of how low-literate consumers process information, make decisions, and cope was essentially non-existent.

Our initial research into low-literate consumers in the US expanded to India next where it grew into examining the entire marketplace in terms of consumers and entrepreneurs. We use the word, entrepreneurs, deliberately here and our work has examined how the 1-1 interactional marketplace works in these settings at the level of exchanges, relationships, and the broader context (Viswanathan et al. 2012). We highlighted how consumers and entrepreneurs are two sides of the same coin, using terminology such as the 'subsistence consumer-merchant' to drive home this point (Viswanathan, Rosa and Ruth 2010). We show the nuance here in differentiating between survival, subsistence, and transformative subsistence entrepreneurs. Our own research has expanded to tribal communities in Tanzania, a refugee settlement in Uganda, and to Latin America. In parallel, a

${ }^{2}$ www.marketplaceliteracy.org/ 
community of scholars has worked in a variety of contexts around the world ranging from urban to rural and tribal and in many different continents. Again, these are profiled at the University of Illinois site: https://business.illinois.edu/subsistence/research/publications/.

\section{Summary of the Subsistence Marketplaces Research \\ Stream}

This brief review is intended to provide a flavor for the nature of insights developed in the subsistence marketplaces stream rather than be exhaustive. References are to the work within the field rather than outside it, given our goal of summarizing this specific stream. We emphasize though, that there is much we have learned from other streams that are beyond the scope of this review.

The subsistence marketplaces research stream has developed through a bottom-up view of subsistence consumers and their marketplaces, to understand consumer needs, usage situations, and life circumstances. This bottom-up approach enables marketing researchers and practitioners from various ideological, theoretical and practical perspectives to immerse tin the unfamiliar subsistence contexts, and develop understanding. This iterative process of immersion and adaptation permits the bottom-up approach to inform the conventional top-down approach adopted for developing marketbased solutions to alleviate poverty (Viswanathan and Sridharan 2009). We provide both an inside-out perspective in keeping with our bottomup approach and an outside-in perspective that is informed by this approach.

\section{The Bottom-Up Approach}

The literature covers a number of aspects to taking a bottom-up approach to understanding subsistence marketplaces requires immersion into the relationships, interactions, needs and contexts in these marketplaces as well as to designing solutions and running enterprises (Viswanathan 2016). Respect for individuals and their relationships, empathy with their situation and sincere listening are critical elements of developing an understanding in these contexts. Approaching these contexts with a willingness to learn and freedom from pre-conceived notions are important requirements for successful immersion. From a researcher's perspective, it becomes important to have flexibility in the chosen research method or research questions, which evolve as the researcher's inductive understanding of the context improves. Similar, from a manager's perspective, there are a number of aspects to developing solutions and implementing them through enterprises. A number of articles in this stream have examined important methodological issues (Ozanne and Saatcioglu 2007). 


\section{Low Literate, Low Income Consumers}

Our understanding of how subsistence consumers think developed from our observation of the buying behavior of low-income and lowliterate consumers (Viswanathan, Rosa and Harris 2005; also see parallel work by Ozanne and Adkins 2005). A fundamental aspect is that low-literate consumers have difficulty in understanding nutrition labels, unit prices, magnitudes and taxes. They also have trouble computing total prices and sometimes even locating products in a shop. We refer to an underlying cognitive predilection as 'concrete thinking or reasoning', whereby consumers have difficulty in drawing more abstract inferences from pieces of information. This difficulty with abstraction limits the ability of subsistence consumers to make computations or complex decisions, which results in sub-optimal purchases (Viswanathan, Rosa and Harris 2005). Another feature of how subsistence consumers think, referred to as 'sight-reading' by one of our informants, is in words and numbers being processed pictographically or as images - sometimes resulting in ingenious ways of processing information to overcome constraints. Whereas pictographic thinking requires imagination, it comes more naturally to consumers relying on a sensory mode to overcome lack of basic literacy or numeracy skills to interpret information commonly available to them. This cognitive predilection is front and center in marketplace encounters.

In order to maintain their sense of self-esteem, subsistence consumers may even be willing to pay more to shop in friendlier settings rather than be exposed for their low literacy. Even in circumstances in which resources are highly limited, subsistence consumers may choose emotional outcomes over economic value or convenience. Interestingly, even as physiological or safety needs of consumers are vital, social and self-esteem aspects are very important for subsistence consumers. Self-esteem can be involved in the most mundane of transactions when coming from a background of low income and low literacy. We have elaborated elsewhere on the role of trade-offs involving emotions (Viswanathan Rosa and Harris 2005; see also parallel work by Adkins and Ozanne 2005) and the importance of trusted relationships (Viswanathan et al. 2012). The role of emotions in a state of survival and subsistence is often counter-intuitive to understand from a background of certainty with respect to day-to-day aspects of life. The emotional aspect is accentuated in refugee settings which overlay subsistence with the most dire of circumstances and a history of war and violence. The focus on the immediate in subsistence contexts because of extreme income constraints and the urgency to fulfill immediate basic needs, is compounded with cognitive constraints, and emotional elements. In a refugee context, narrowing to the present 
is further exacerbated by a violent past and the fear of hoping for a better future.

The cognitive predilections described earlier along with selfesteem maintenance may result in dependence on others to make choices or decisions. Dependence is one of the ways subsistence consumers adopt to cope with their limitations and a wide array of uncertainties in the marketplace in their daily lives.

Thus, our approach provides a pathway for contribution from marketing as a discipline to poverty alleviation and development - by unpacking poverty at the micro-level in terms of its strong correlates, such as low literacy. This means unpacking umbrella terms such as social capital as well. Poverty is so much about uncertainty in the most mundane of life circumstances and the lack of a fallback or a cushion (Viswanathan 2013). Understanding these life circumstances at the micro-level was the starting point for our research.

Such unpacking lead to the insights about how poverty is not about the material alone but about the thinking, feeling, and consequent coping (cognitive, affective, and behavioral) as well (Viswanathan, Rosa and Harris 2005). Income constraints and the urgency to fulfill immediate basic needs, cognitive constraints, and emotional focus combine to lead to a focus on the immediate. An interesting case in point is when we provide our marketplace literacy educational program and women speak to how they will change and improve in their buying habits. In response to our query as to why such behavior was not engaged in before the educational program, one woman said she never thought of herself as a customer until then. She thought of herself as someone who buys and the shopkeeper as someone who sells. This insight points to the notion of what we take for granted - the richness of the concepts we possess as a result of our exposure, education, and experience. Indeed, for us, the notion of a customer is embedded with rights, with skills and knowledge, and with self-confidence (Viswanathan, Sridharan and Ritchie 2009). Thus, poverty is not only about the material, it is about the mental and the psychological - which plays out in realms such as being a consumer in the subsistence context (Viswanathan and Rosa 2010). We summarize these cognitive constraints in terms of concrete thinking and pictographic thinking in the next section.

\section{Subsistence Consumers, Entrepreneurs and Marketplaces}

To understand subsistence consumers and entrepreneurs, the harsh reality life circumstances of poverty need to be understood at a micro level. A distinct feature of poverty is chronic uncertainty, that gets exacerbated by transient shocks that may occur with untoward emergencies or calamities (Venugopal et al. 2015). This uncertainty 
places people in a cycle of negotiation between unanticipated events and actions with uncertain outcomes. The lack of a social or economic 'cushion' makes the downside of events and actions intense and significant. Within this cycle of uncertainty, subsistence consumers live, think, cope, relate and negotiate in the marketplace.

Subsistence entrepreneurs operate small businesses in contexts of poverty for the primary purpose of survival. Consumers and entrepreneurs have been described as two sides of the same coin, as entrepreneurs and consumers share adversity in a 1-1 interactional environment, and being an entrepreneur is often the primary path to surviving and subsisting (Viswanathan et al. 2012). Research in this stream has examined a variety of issues relating to such topics as consumption (Ruth and Hsiung 2007), entrepreneurship (JonesChristensen, Parsons and Fairbourne 2010; DeBerry-Spence and Elliot 2012), community empowerment (Lindeman 2014), and sustainability (Dhanda and Hill 2007). Entrepreneurs in subsistence contexts operate within in the highly interconnected social milieu of subsistence consumers, and are deeply affected by their consumers' and their own financial difficulties and extraneous uncertainties (hence, the conventional 'buyer-seller' distinction may not apply). This interconnectedness manifests through strong personal-level consumer relationships, where entrepreneurs are familiar with individual needs of the consumers they interact with. Credit-based relationships help consumers overcome immediate financial stresses and help entrepreneurs widen their consumer base and strengthen consumer loyalty (Viswanathan, Rosa and Ruth 2010). Such relationships allow for compromise with both the quantity or quality of products through fluid transactions. In such marketplaces built on relationships and mutual dependence, there is intense bargaining, wide disparities in information access and many instances of entrepreneurs taking advantage of consumers' vulnerabilities. Our research has also led to nuanced understanding of survival, subsistence, and transformative entrepreneurs, the latter enhancing their economic well-being and often that of their communities as well. The underlying process through which such entrepreneurship unfolds has been documented as well (Sridharan et al. 2014). We use the term, entrepreneurs, deliberately and highlight means entrepreneurs as distinct from ends entrepreneurs and distinguish between survival, subsistence, and transformative entrepreneurs (Viswanathan and Venugopal 2015).

In resource-constrained contexts, allocation of resources by both consumers and entrepreneurs is critical. However, given the highly uncertain and varying nature of the marketplace environment, available resources are highly fungible and may be put to use to meet a variety of ends - all of which are not always pre-determined. In other words, there are no clear 'compartments' or 'domains' of expenditure; 
resources are allocated to multiple 'compartments' based on the immediate need or priority (Viswanathan and Rosa 2007). As noted earlier, one-to-one relationships in subsistence marketplaces form the basis of how subsistence marketplaces function. Human relationships and mutual trust are paramount when both consumers and entrepreneurs have cognitive difficulties and are vulnerable to making erroneous judgements or getting cheated. This nature of human relationships ensures high responsiveness to each other's' needs as the interaction is frequent and intense. The responsiveness to needs brings in two aspects of marketplace exchanges: customized transactions and fluidity of transactions (Viswanathan et al. 2012). In order to be responsive to the needs and paying capacities, entrepreneurs may customize the nature of the product (in terms of its quality), quantity, instalments of payment, mode of payment or even the cost depending on the consumer. This flexibility encourages the consumer to bargain heavily - leading to many aspects of the transaction being decided on the spot and with high variance ('fluidity') in the transaction from place to place and from time to time. This nature of relationships, the extent of interdependence and the constant struggle to survive brings an element of empathy that entrepreneurs (sellers) have for consumers (buyers) and vice versa, making marketplace relationships more enduring than in non-subsistence contexts. The highly relational marketplace is embedded within the social milieu of human relationships. Conversely, the conflicts and differences at the social level seep into marketplace interactions between and among entrepreneurs and consumers. Thus, developing an understanding of the marketplace requires an appreciation of the social context that the marketplace functions in.

In terms of a bottom-up view of sustainability, consumers and entrepreneurs living in subsistence seek to survive, relate and grow (Viswanathan et al. 2014). Here again, rather than place a top-down framework of sustainability, this stream seeks to understand what people living in subsistence are trying to sustain.

\section{Developing Products \& Enterprise Models for}

\section{Subsistence Marketplaces}

As noted, our bottom-up approach provides a grounding to consider solutions outside-in. We provide an overview here. In terms of products and businesses, and markets, research in this stream has examined a number of issues ranging from creation of markets (Abdelnour and Branzei 2007), to social entrepreneurship (Azmat, Ferdous and Couchman 2015), market orientation (Burgess and Nyajeka 2007), alliances and institutions (e.g., Kolk and Lenfant 2015). The approach for developing sustainable solutions for subsistence contexts requires an understanding of the needs, drivers, and larger context elements 
that determine consumer behavior. Often, it is not sufficient to understand the consumer alone, as life circumstances and the social milieu are intertwined with product usage situations (Viswanathan, Seth, Gau and Chaturvedi 2009). Thus, the notion of focusing on consumer needs also requires broadening in these contexts. Life circumstances over and above usage situations need to be analyzed in order to understand consumption and product use (Viswanathan and Sridharan 2012). Consumers, communities, and larger contexts need to be understood in concert. In designing products, the entire ecosystem has to be considered to enable use of the product by consumers who are facing deprivation on multiple fronts (Viswanathan and Sridharan 2012). Hence, a product ecosystem that encompasses extrinsic elements such as networks, support, and education must be considered during product development. In effect, product design and development of business models must go hand-in-hand for subsistence marketplaces.

In a subsistence context, consumer choice is often between purchasing a product, making it (including by using a substitute that they already have) or foregoing purchase (Viswanathan et al. 2009). Value propositions need to clearly communicate what consumers need to 'give', and what they 'get' while purchasing a product, addressing the cognitive tendencies of subsistence consumers such as 'concrete thinking'.

Furthermore, both basic and aspirational needs of consumers should be considered, the latter being both brand and life aspirational. A better future for the next generation is a strong aspiration for subsistence consumers for a variety of sometimes seemingly mundane products, such nutritional alternatives. As noted, usage situations need to be anticipated where possible while allowing for emergent uses and situations that neither the designer nor the user can anticipate. The need for constant customization at point of purchase and use is another aspect for product design.

The business model developed around the product must stem from household, community-relational, and marketplace-social levels of analysis. Products are viewed as instruments for betterment of life circumstances by households, over and above the immediate needs that the products serve. The business model must cater to the 1-1 interactional nature of the marketplace and the inter-relationships between consumers and entrepreneurs. The overall social dynamics of the community must be taken into account while designing the business model. We push the notion of doing good and doing well to the point of how product-relevant social good may be essential for doing well (Viswanathan et al. 2009). Business have to reflect the blurring at product, relationship, and marketplace levels in understanding social good as a common denominator and 
incorporating it into how they understand subsistence marketplaces and design solutions.

\section{Implications of the Subsistence Marketplaces Stream Teaching Marketplace Literacy in Poverty Contexts}

Our earliest foray into using our research for education for the communities we worked in was in the realm of creating nutrition educational materials in the state of Illinois. However, our work in India led to developing the concept of marketplace literacy and an educational program to provide it (Viswanathan et al. 2009). At its core, marketplace literacy is not basic literacy; it is socially embedded functional literacy in the marketplace - as consumers and as entrepreneurs (Viswanathan, Gajendiran and Venkatesan 2008). It covers skills/knowledge, self-confidence, and awareness of rights. This notion came about from our observation that there were no programs that addressed the cognitive and emotional aspects we touched on earlier. Thus, we focused on providing people with the ability to think more abstractly about marketplaces by focusing on deeper understanding or know-why - why do marketplaces work the way they do, why should I gauge the give and get (value) as a customer, why should I be customer oriented as an entrepreneur, or why should I choose a particular business. The aim here was that such education, say on what a value chain is, will enable individuals to envision beyond the immediate - the realm where they have had the most exposure (Viswanathan, Gajendiran and Venkatesan 2008). Marketplace literacy encompasses what (to buy or sell including livelihoods, how (say, to keep accounts, or communicate about products), and why (say, to be customer oriented) - our program emphasizes the why as a starting point to then cover the how and the what. Our oversimplified view is that there are three central aspects that can enable individuals to participate as customers and entrepreneurs in subsistence marketplaces - financial resources, access to enable participation in value chains and fair exchanges, and marketplace literacy (Viswanathan et al. 2009).

The marketplace literacy education now reaching eight countries and more than 40000 individuals through work with our partners encompasses a number of marketing concepts. Why Marketing? Because we address the needs of those at the bottom (Zero to $12^{\text {th }}$ grade education and low income), and what they need most; the first layer of the onion, so to speak, is about customers and marketplaces. We cover the notion of an exchange, how exchanges add up to a value chain, how there are different needs, how they are satisfied through goods and services, how groups of customers are different, how a customer orientation is critical and that there is no business without a customer, how to be an effective customer by getting value in 
exchanges, how to deliver value through mutually beneficial exchanges as an entrepreneur, how to gather information and understand customers and the marketplaces, how ingredients in product design should lead to benefits, how to communicate about the product, how to deliver it, how to price for addressing value and how to balance societal needs including the environment, as well as some generic issues in business (finance and accounting). This first layer approach emphasizing marketing speaks to the core aspects of business that begin with a consumer focus. It also emphasizes the crucial role that marketing can play in poverty alleviation and development.

What we teach is not new certainly to Marketing, but how is fundamentally different. Our approach is fundamentally bottom-up. As a case in point, we don't teach market segmentation as a concept, rather, we stitch it together bottom-up based on whom a product can be sold to first, then next, and how people are different. To emphasize customer needs, we use a picture sorting on what element is most important to start a business, using pictures of money and various elements of a value chain. Participants typically choose money as the most important element. But through discussion they understand that a business can be started without money but it can never be started without a customer. Participants learn how to be an effective customer and get value in an exchange before understanding how to be an entrepreneur and deliver value.

The biggest and most widespread impact we see is in monetary savings and better quality products (e.g., avoiding expired medicine) obtained by being better customers. This impact is immediate and nearly universal in our judgment (Viswanathan et al. 2009). This is a distinctly different pathway to consider marketing and poverty alleviation, i.e., from the bottom-up through individuals learning about aspects of the marketplace. Yet, it is consistent with the core focus of the marketing discipline. A subset of participants start or expand income-generating activities, typically through micro-enterprises.

However, we also expand notions from marketing to other realms of life. We use the intuitive, concrete consumer context to develop the notion of value - the give and the get. We expand the give beyond the monetary to time and effort, and the get beyond the product to trusted relationships, and support. We then extend the notion of value in an exchange to the domain of the entrepreneur, and the employee. We also extend the notion to using resources to reduce waste outside the realm of marketplace exchanges. We further extend the notion to the realm of the local environment in terms of giving and getting. We extend the notion to relationships. And finally, we extend the notion to life aspirations - investment and reward for long-term goals, particularly relevant for young people. Thus, we have developed the notion of value beyond the marketing domain to different realms of 
life. As we note later, a compartmentalized approach may fit relatively resource-rich settings but marketplaces and lives are intertwined in subsistence contexts (Viswanathan, Sridharan and Ritchie 2010).

\section{Curricular Innovations on Subsistence Marketplaces}

As noted earlier, our research provided the foundation for designing marketplace literacy education for subsistence communities. This work also has implications for curricular innovations for students in and beyond marketing with its unique disciplinary stamp, including areas such as management, as well as in design, engineering, and other areas. These curricular innovations challenge students to confront global problems and envision a better world, adopting a conception of business that focuses on finding win-wins between different dimensions of sustainability while acknowledging trade-offs, and emphasizing a pragmatic focus on doing sustainability. A yearlong, innovative inter-disciplinary graduate-level course on sustainable product and market development for subsistence marketplaces with international immersion (ranked one of the top entrepreneurship courses by Inc. magazine) serves as a unique platform for bottom-up innovations for companies and social enterprises, with about 50 projects to date over more than 10 years involving interdisciplinary groups combining marketing/business, design, engineering, and other areas. Insights from projects are being implemented by some sponsor enterprises, including potential commercialization of specific prototypes.

Additionally, a module on professional responsibility in the face of global challenges has been designed and offered for all (approximately 600) first semester undergraduate business students for more than a decade now. Other courses include an executive MBA course on Global Business Horizons, focused on subsistence and sustainability, and a first semester course for undergraduate engineering students entitled Engineering for Global Development.

A web portal shares educational materials with educators, students, and practitioners; and is available at https://business.illinois.edu/subsistence/Resources/Resourcesmlp/ , with day-in-the-life videos, movie, multimedia immersion exercises, qualitative interviews, project reports). An online course on subsistence marketplaces is reaching tens of thousands of students around the world through Coursera. Service learning experiences have also benefited from the understanding of subsistence contexts and design of international immersion experiences. A module has also been designed to be part of training for UNHCR staff on subsistence marketplaces. All these learning experiences share the uniquely bottom-up approach that characterizes this stream. Thus, the learning experiences begin with a deep understanding of radically different 
marketplaces, capturing the Marketing perspective in this sense and reaching out to diverse audiences working on poverty alleviation. Whereas we speak of work we have been involved in, we note that a number of educators around the world are incorporating subsistence marketplaces into their offerings to different degrees.

\section{Applications in Other Contexts}

Our learning from subsistence contexts has been applied to nonsubsistence contexts and in higher education. Some directions include: (a) what has been termed reverse innovation (Govindarajan and Trimble 2012) or upward innovation, as even illustrated with our own marketplace literacy program, (b) translation of product solutions and business models from subsistence to non-subsistence contexts, and (c) employment of the bottom-up approach developed in subsistence contexts to non-subsistence contexts (Viswanathan 2016). Products developed in subsistence contexts involve a high level of creativity. Insights here can generalize to advanced economies in informing the product development process. Finally, bottom-up approaches are very relevant to marketing in non-subsistence contexts. Immersion in the marketplace helps managers better understand their clientele or consumer base and also involve people at the bottom of the organization. And insights for sustainable marketing balancing social and environmental goals can emerge from learning in subsistence marketplaces where these issues play out starkly.

\section{Discussion on Marketing and Development}

The insights we have developed from our bottom-up approach appropriately translate to a variety of marketing functions that we have documented in detail elsewhere and are reflected in an array of courses we have developed. In brief, we have developed an approach that covers bottom-up immersion (virtual and actual), emersion, design, and enterprise. The role of bottom-up immersion is to move practitioners and researchers from sympathy to informed empathy. We have provided many detailed and specific guidelines and materials for such immersion (Viswanathan 2016). Emersion refers to stretching the concepts previously learned in marketing (or other disciplines) in relatively resource-rich settings to subsistence marketplaces or creating new concepts. As a case in point, the marketing literature speaks of consumer needs and usage situations. The former in subsistence marketplaces is embedded within household, community and social milieu, and large context elements fraught with uncertainty, lacking infrastructure and institutional mechanisms. We emphasize life circumstances and the uncertain nature of needs and usage situations. We note that notions of optimizing product design do not apply when the designer does not know the context, and nor does the user as the 
usage situation evolves based on day-to-day uncertainties (Viswanathan and Sridharan 2012). Put differently, distinct here is the need to design, not so much for a product to fit a set of known usage situations, with understanding of available infrastructure (say microwave in a kitchen), but to design for uncertain, evolving, and emergent uses in a variety of situations (stove in the floor of a hut multiple uses, cross-purposes). Thus, consumer needs expand to consumer, community and larger context, and usage situations expand to life circumstances. Additionally, we note that products have to address needs as well as aspirations, the latter being both brand and life aspirations (Venugopal and Viswanathan 2015). This is an important way in which marketing has a role in poverty alleviation in the face of multi-faceted deprivations, through understanding life aspirations, community development, and social good.

We also argue at the enterprise level for the inherent role of social good as it relates to the need and the offering (Viswanathan et al. 2009). Products blur with betterment of basic life circumstances, relationships blur the economic and the social, and marketplaces blur with the social milieu. This has implications for understanding needs, designing solutions, and implementing them. In summary, Marketing in a world of blurred boundaries is fundamentally different from marketing in a compartmentalized world. Going beyond doing good and doing well, doing good as it relates to the product and its ecosystem may be essential in order to do well (Viswanathan et al. 2009).

Achrol and Kotler (2016) discuss how marketing models can help improve the consumption capacity and quality of life of low income consumers across the world. Marketing is being increasingly viewed as a potent and effective instrument to further social welfare and poverty alleviation, playing a more central role in the development discourse. Broadly, there are three reasons that justify the use of marketing as a tool to fight poverty - (a) marketplaces can empower consumers and entrepreneurs socially and economically in subsistence marketplaces; (b) investing in marketplace exchange-based approaches for development may yield more sustainable and self-perpetuating impact that complement other approaches; and (c) marketplaces allow for greater participation of the 'beneficiary' community. The potential of consumer research to develop innovative mechanisms for poverty alleviation within the context of the marketplace has also been captured with the transformative consumer research stream of literature (Mick et al. 2012; Shultz et al. 2012). For instance, Blocker et al. (2012) develop a transformative consumer research framework for expanding the current understanding of mechanisms for poverty alleviation. They include consumer choice, product experiences, consumer culture, marketplace forces and consumption capabilities as research streams to integrate in the framework. 
Marketplaces have forever been an inextricable part of the social, cultural and economic lives of the poor across the globe. Characterizations of such marketplaces as informal, fragmented or disorganized, notwithstanding, they provide means for families to meet their daily needs through economic exchange and buyer-seller relationships. These marketplaces, just as their participating stakeholders, have unique characteristics that make them very different than what managers encounter and academics study in their professions. Further, the finer characteristics of these marketplaces may differ from community to community or village to village, making it difficult to develop a complete or 'one-size-fits-all' solution. These marketplaces are complex as social interactions are intertwined with economic transactions, and the marketplace is blurred with the social milieu.

We call such marketplaces in the broad range of low income, 'subsistence marketplaces'. Again, given the complex nature of such marketplaces, there is an entire spectrum of 'low-income' buyers and sellers who form the fabric of these marketplaces - from those who are barely surviving to those who are moving up the ladder of poverty to lower-middle income status. To avoid getting an incomplete view of this marketplace, we take a broad qualitative view of 'subsistence' than a view defined by clear quantitative metrics or pre-determined 'levels'. We observe that the lines between the marketplace and the social context of the community blur at the level of buyer-seller interactions. Such marketplace contexts range from urban to semi-urban, rural, tribal, refugee settlements, as well as conflict regions. A top-down view of these marketplaces from the broader stand-point of government policy or organizational business strategy provides limited perspective in developing deeper understanding of these marketplaces. Hence, we start at the micro-level level of consumers and entrepreneurs engaging with these marketplaces, developing insights on their behavior, needs and social interactions in the process. We employ these insights in developing product and business solutions that can help organizations to develop products and business models for subsistence marketplaces. Hence, this approach that starts with insights at the micro-level, and then uses such insights at the organizational level, i.e., 'bottom-up' - which is the defining characteristic of our approach to understanding subsistence marketplaces.

The bottom-up approach enables inductive learning from data and observation rather than viewing situations through preconceived notions of development or marketing. We amalgamate marketing and other business responses from the bottom-up (bottom-up planning and implementation) rather than use a traditional top- down approach. Our central point here is not that bottom-up approaches are superior to topdown approaches. Rather, the bottom-up approach is often neglected 
and more difficult, but addresses a substantial gap when working with unfamiliar and fundamentally different, resource-constrained contexts fraught with uncertainty - in this case, the subsistence context. Our top-down knowledge has been created in relatively resource-rich contexts with relative certainties, and it applies to these more familiar contexts, but not necessarily to poverty contexts. These more familiar contexts are developed, and share commonalities of progress and development often tied together by material needs that apply to middle and upper classes globally. They share educational commonalities that bridge differences, infrastructures that draw on progress in science and technology, and institutional mechanisms that are based on some degree of shared knowledge. Subsistence marketplaces do not have infrastructure and institutional mechanisms that are shared or part of common knowledge in relatively affluent parts of the world, and don't share the degree of education that the developed world does. Depending on the degree of isolation, tribal communities even more so than, say, other rural communities or semi-urban communities, do not have the same shared knowledge that comes from education. Finally, the connectedness within these communities represents an amplified version of any word-of-mouth in relatively affluent communities, particularly before the onset of the Internet age. Such a world of oneon-one interactions emphasizes a balance of both top-down and bottom-up approaches to develop marketing solutions.

Our insights from the subsistence marketplaces can be applied to other contexts, including to resource-rich settings. Innovation from the subsistence contexts can flow to advanced economies, or between income segments within an economy. Products developed under resource-constrained settings require a high level of creativity. This can inform product development processes being utilized for higher-income markets. In some cases, products developed for low-income segments can be directly used for higher-income segments, as the usage situations of the product may be universal. Immersion in the marketplace to understand buyer-seller relationships can also help managers understand their clientele or consumer base better, leading to more informed marketing decisions. Moreover, in the face of environmental degradation that may result in an uncertain future, using marketing insights from subsistence marketplaces may help in decision making in situations where uncertainty is a central, determining feature.

\section{Conclusion}

We applaud the different efforts to consider the role of marketing in poverty alleviation, including the multiple contributions in MGDR. We highlight above, a different pathway, that begins at the most logical point in some ways from the perspective of the marketing discipline, by gaining bottom-up insights about the end-beneficiaries of poverty 
alleviation efforts. Indeed, it is this need that drove the development of this stream of work at the intersection of poverty and marketplaces. What we have learned resonates in terms of topics with the field of marketing, although challenging us to consider new forms of thinking, feeling, and acting that stretch the imagination from the perspective of our experiences and day-to-day lives. This pathway may well be as important as any contribution that marketing can make to development efforts. Marketing is about customers and marketplaces and beginning with the customer. That is what we have done, in a sense, with our work. But learning about the customer also means learning about the community and the larger context in settings which are distinctly different from each other and filled with uncertainties, and which marketers are unfamiliar with.

Interestingly, the biggest need we have addressed is through designing education to address marketplace literacy covering a number of marketing concepts, but while being bottom-up. The need to learn elements of the marketplace covered in marketing is the first layer for those living in poverty to participate in the marketplace - as customers and as entrepreneurs. Such learning enhances self-confidence, increases awareness of rights, and develops skills and knowledge. This pathway as well may be as important as any contribution that Marketing can make to development efforts. It too is very consistent with addressing the needs of the end beneficiaries, the customers. Marketing concepts provide intuitive, concrete starting points to address other aspects of development, as we do with the concept of value.

Our insights for marketing also being bottom-up, translate to product design and enterprise development. We note the role of social good and the need to blur boundaries and consider life circumstances (consumers, communities, larger context) in considering product design in settings fraught with uncertainty with evolving usage situations.

In closing, we note with great humility that poverty alleviation is as challenging as anything that confronts the global community in the $21^{\text {st }}$ century, much more so now compounded with enormous environmental challenges. Marketing, along with many other disciplines, has an important role in the ongoing journey toward a world with alleviated poverty. Our experience that we relate above is just that - it draws from learning, teaching, and doing. Our impact is minuscule quantitatively but the lessons learned can be used elsewhere. And the lessons we have learned resonate with the Marketing discipline in fundamental ways. 


\section{References}

Abdelnour, Samer and Oana Branzei (2010), "Fuel-efficient Stoves for Darfur: The Social Construction of Subsistence Marketplaces in post-conflict settings," Journal of Business Research, 63 (6), 617-29. https://doi.org/10.1016/i.jbusres.2009.04.027

Achrol, Ravi and Philip Kotler (2016), "Marketing's Lost Frontier: The Poor," Markets, Globalization \& Development Review, 1 (1), Article 3. https://doi.org/10.23860/MGDR-2016-01-01-03

Achrol, Ravi S. and Philip Kotler (2017), "Extending the Marketing Dialog on Poverty," Markets, Globalization \& Development Review, 2 (1), Article 6. https://doi.org/10.23860/MGDR-2017$\underline{02-01-06}$

Azmat, Fara, Ahmed Shahriar Ferdous and Paul Couchman (2015), "Understanding the Dynamics Between Social Entrepreneurship and Inclusive Growth in Subsistence Marketplaces," Journal of Public Policy \& Marketing, 34 (2), 252-71. https://doi.org/10.1509/jppm.14.150

Blocker, Christopher P., Julie A. Ruth, Srinivas Sridharan, Colin Beckwith, Ahmet Ekici, Martina Goudie-Hutton, José Antonio Rosa, Bige Saatcioglu, Debabrata Talukdar, Carlos Trujillo and Rohit Varman (2013), "Understanding poverty and promoting poverty alleviation through transformative consumer research," Journal of Business Research, 66 (8), 1195-1202. https://doi.org/10.1016/j.jbusres.2012.08.012

Burgess, Steven Michael, and Pfavai Nyajeka (2007), Market orientation and performance in low-income countries: The case of Zimbabwean retailers, in José Antonio Rosa, Madhubalan Viswanathan (eds.) Product and Market Development for Subsistence Marketplaces (Advances in International Management, Volume 20, Emerald Group Publishing Limited, 215-57.

DeBerry-Spence, Benet and Esi Abbam Elliot (2012), "African Microentrepreneurship: The Reality of Everyday Challenges," Journal of Business Research, 65 (12), 1665-73. https://doi.org/10.1016/j.jbusres.2012.02.007

Dhanda, Kanwalroop Kathy and Ronald Paul Hill (2007), "Consumption and Environmental Degradation: A Long-term View," in Product and Market Development for Subsistence Marketplaces (Advances in International Management), José Antonio Rosa, Madhubalan Viswanathan, eds. Volume 20, Emerald Group Publishing Limited, 297-317. 
Govindarajan, Vijay and Chris Trimble (2012), Reverse innovation: Create far from home, win everywhere. Boston: Harvard Business Review Press.

Jones-Christensen, Lisa, Helen Parsons, Jason Fairbourne (2010), "Building Entrepreneurship in Subsistence Markets: Microfranchising as an Employment Incubator," Journal of Business Research, 63 (6), 595-601. https://doi.org/10.1016/j.jbusres.2009.03.020

Karnani, Aneel (2017), "Marketing and Poverty Alleviation: The Perspective of the Poor," Markets, Globalization \& Development Review, 2 (1), Article 5. https://doi.org/10.23860/MGDR-2017$\underline{02-01-05}$

Kolk, Ans, and François Lenfant (2015), "Cross-Sector Collaboration, Institutional Gaps, and Fragility: The Role of Social Innovation Partnerships in a Conflict-Affected Region," Journal of Public $\begin{array}{llll}\text { Policy \& Marketing, } 34 & \text { (2), 287-303. }\end{array}$ https://doi.org/10.1509/jppm.14.157

Lindeman, Sara (2014), "Until We Live Like They Live in Europe: A Multilevel Framework for Community Empowerment in Subsistence Markets," Journal of Macromarketing, 34 (2), 17185. https://doi.org/10.1177/0276146713514753

Mandiberg, James, and Richard Warner (2012), "Business development and marketing within communities of social service clients," Journal of Business Research, 65 (12), 1736-42. https://doi.org/10.1016/i.jbusres.2012.02.015

Mick, David Glen, Simone Pettigrew, Cornelia Connie Pechmann and Julie L. Ozanne, eds. (2012), Transformative consumer research for personal and collective well-being. Routledge.

Ozanne, Julie L. and Bige Saatcioglu (2007), "Understanding Subsistence Marketplaces: Exploring the Contributions of Participatory Action Research," in Product and Market Development for Subsistence Marketplaces: Consumption and Entrepreneurship Beyond Literacy and Resource Barriers, Jose Rosa and Madhu Viswanathan, eds. Advances in International Management Series, Joseph Cheng and Michael Hitt, Series Editors, 111-32, Elsevier. 
Ruth, Julie A. and Rachel Oakley Hsiung (2007), "A Family Systems Interpretation of How Subsistence Consumers Manage: The Case of South Africa," in Product and Market Development for Subsistence Marketplaces: Consumption and Entrepreneurship Beyond Literacy and Resource Barriers, Jose Rosa and Madhu Viswanathan, eds. Advances in International Management Series, Joseph Cheng and Michael Hitt, Series Editors, 59-87, Elsevier.

Shultz, Clifford J., Rohit Deshpandé, T. Bettina Cornwell, Ahmet Ekici, Prabakar Kothandaraman, Mark Peterson, Stanley Shapiro, Debabrata Talukdar and Ann Veeck (2012), "Marketing and public policy: Transformative research in developing markets," Journal of Public Policy \& Marketing, 31 (2), 178-84. https://doi.org/10.1509/jppm.11.007

Sridharan, Srinivas, Elliot Maltz, Madhu Viswanathan and Samir Gupta (2014), "Transformative Subsistence Entrepreneurship: A Study in India," Journal of Macromarketing, 34 (4), 486-504. https://doi.org/10.1177/0276146714529659

Toledo-López, A., Rene Díaz-Pichardo, Julio C. Jiménez-Castañeda and Patricia S. Sánchez-Medina (2012), "Defining success in subsistence businesses," Journal of Business Research, 65 (12), 1658-64. https://doi.org/10.1016/j.jbusres.2012.02.006

Viswanathan, Madhubalan (2013), Subsistence Marketplaces, eBookpartnership, eText, and Stipes Publishing.

Viswanathan, Madhubalan (2016), Bottom-Up Enterprise: Insights from Subsistence Marketplaces, eBookpartnership, eText, and Stipes Publishing.

Viswanathan, Madhubalan, S. Gajendiran and R. Venkatesan (2008), Enabling Consumer and Entrepreneurial Literacy in Subsistence Marketplaces, Dordrecht: Springer.

Viswanathan, Madhu, Kiju Jung, Srinivas Venugopal, Ishva Minefee and In Woo Jung (2014), "Subsistence and Sustainability: From Micro-Level Behavioral Insights to Macro Level Implications on Consumption and the Environment," Journal of Macromarketing, 34 (1) 8-27. https://doi.org/10.1177/0276146713499351 
Viswanathan, Madhubalan, and Jose Rosa (2007), "Product and Market Development for Subsistence Marketplaces: Consumption and Entrepreneurship Beyond Literacy and Resource Barriers," in Product and Market Development for Subsistence Marketplaces: Consumption and Entrepreneurship Beyond Literacy and Resource Barriers, Jose Rosa and Madhu Viswanathan, eds. Advances in International Management Series, Joseph Cheng and Michael Hitt, Series Editors, 1-17, Elsevier.

Viswanathan, Madhubalan, Jose Antonio Rosa and James Harris (2005), "Decision Making and Coping by Functionally Illiterate Consumers and Some Implications for Marketing Management," Journal of Marketing, 69 (1), 15-31. https://doi.org/10.1509/jmkg.69.1.15.55507

Viswanathan, Madhubalan, Jose Antonio Rosa, and Julie Ruth, "Exchanges in Marketing Systems: The Case of Subsistence Consumer Merchants in Chennai, India," Journal of Marketing, 74 (3), 1-18. https://doi.org/10.1509/jmkg.74.3.1

Viswanathan, Madhubalan, Anju Seth, Roland Gau and Avinish Chaturvedi (2009), "Ingraining Product-Relevant Social Good into Business Processes in Subsistence Marketplaces: The Sustainable Market Orientation," Journal of Macromarketing, 29 (4), 406-25. https://doi.org/10.1177/0276146709345620

Viswanathan, Madhubalan and Srinivas Sridharan (2012), "Product Development for the BoP: Insights on Concept and Prototype Development from University-Based Student Projects in India," Journal of Product Innovation Management, 29 (1), 52-69. https://doi.org/10.1111/j.1540-5885.2011.00878.x

Viswanathan, Madhubalan and Srinivas Sridharan (2009), "From subsistence marketplaces to sustainable marketplaces: a bottom-up perspective on the role of business in poverty alleviation," Ivey Business Journal, 73 (2), 1-15.

Viswanathan, Madhubalan, Srinivas Sridharan, Roland Gau and Robin Ritchie (2009), "Designing Marketplace Literacy Education in Resource-Constrained Contexts: Implications for Public Policy and Marketing," Journal of Public Policy and Marketing, 28 (1), 85-94. https://doi.org/10.1509/jppm.28.1.85

Viswanathan, Madhubalan, Srinivas Sridharan, Robin Ritchie, Srinivas Venugopal and Kiju Jung (2012), "Marketing Interactions in Subsistence Marketplaces: A Bottom-Up Approach to Designing Public Policy," Journal of Public Policy and Marketing, 31 (2), 159-77. https://doi.org/10.1509/jppm.11.049 
Viswanathan, Madhubalan, and Srinivas Venugopal (2015), "Subsistence Marketplaces: Looking Back, Looking Forward" Journal of Public Policy \& Marketing, 34 (2), 228-34. https://doi.org/10.1509/jppm.34.2.86

Viswanathan, Madhubalan, Ali Yassine and John Clarke (2011), "Sustainable Product and Market Development for Subsistence Marketplaces: Creating Educational Initiatives in Radically Challenging Contexts," Journal of Product Innovation Management, 28 (4), 558-69. https://doi.org/10.1111/j.15405885.2011.00825.x

Yurdakul, Dicle, Deniz Atik and Nikhilesh Dholakia (2017), "Redefining the bottom of the pyramid from a marketing perspective," Marketing Theory, 17 (3), 289-303, https://doi.org/10.1177\%2F1470593117704265 